\title{
"CON USTEDES SOY HERMANO Y PARA USTEDES SOY PASTOR"
}

Hna. Monserrat López SC

Entrevista

\section{Hermana Monserrat ¿Desde cuándo conoce usted a Sergio Contreras?}

Yo a don Sergio lo conozco prácticamente desde que llegó a Temuco. Yo recuerdo que era abril de 1978, cuando yo volvía de Europa. Ese año, después de haber estado durante muchos años en Europa sirviendo a mi Congregación, fui destinada a Temuco: don Sergio habia llegado en Enero. No pasó una semana cuando ya la secretaria de don Sergio me invitó a una reunión con él. Fue el primer encuentro que tuve con don Sergio. Se trató de una reunión Pastoral. En ese primer encuentro lo encontré distante de uno. No se llegaba a un diálogo muy rápido con él. Con el correr de los años y después de trabajar de modo muy cercano a èl en la Pastoral diocesana, la gran sorpresa fue descubrir que uno puede dialogar mucho con él, conversar mucho con él.

\section{¿Cuál cree usted que han sido los aportes más importantes de Don Sergio a la Diócesis?}

Creo que los dos aportes más importantes que deja don Sergio a la Diócesis fueron su fuerte compromiso con los Derechos Humanos - don Sergio se la jugó por los Derechos Humanos- y la organización de la Diócesis, especialmente de la Pastoral de Conjunto. Don Sergio nos deja una Diócesis donde pastoralmente todo está organizado y será responsabilidad nuestra continuar con ello, habrá cosas nuevas, pero yo sé que estas dos lineas se van a continuar. Me recuerdo que para avanzar adecuadamente en la organización pastoral diocesana, don Sergio trajo peritos que nos ayudan a planificar, -aprendimos a planificar-y hasta el dia de hoy todo lo planificamos.

Yo tengo un especial recuerdo de estos años, son las Semanas Sociales que en un tiempo en que las circunstancias politicas del pais aconsejaban no realizarlas, esta fue la única diócesis donde se hicieron. Yo era Directora del Departamento de Educación de la diócesis y como tal nos tocó organizar las jornadas sociales, le cambiamos el título no la llamamos 
asi, le pusimos: "El Pensamiento Social de Juan Pablo II", con ese titulo tuvimos las Semanas Sociales. Sentimos constantemente su apoyo, estuvo presente en cada reunión que tuvimos en esa semana. Él estaba ahi, no hablaba, estaba ahi y eso nos daba ánimo para seguir trabajando. La figura de Don Sergio se alzaba con mucha fuerza en aquella epoca.

Ese apoyo "de atrás" ha sido una de sus caracteristicas en el trabajo pastoral de don Sergio, no tanto de palabras sino de hechos.

\section{¿Cómo fue la relación de Don Sergio con la Vida Religiosa?}

En los ańos que yo tuve la CONFERRE, nunca le pedimos algo que nos haya dicho que no. Los retiros que le pedimos para las religiosas. ahi estaba don Sergio. nos daba los retiros y generaimente retiros muy, muy buenos, a la luz de algun documento de la Iglesia. Siempre nos dijo a nosotras las religiosas: "Vivan su consagración con mucha sobriedad, humildad y alegria" y remarcaba la palabra "alegria", no sé si será porque somos medios tristes.

Siempre que le pedimos como religiosas su presencia en una fiesta, él nunca se negó. Siempre estaba ahi, participó de la vida de familia de cada una de las congregaciones, incluso de los momentos tristes, por ejemplo yo lo he visto muchas veces cuando han muerto hermanas acompañandonos hasta el cementerio. Estuvo con nosotros en el momento de gozo y de dolor. La sensibilidad frente al dolor es muy caracteristico en don Sergio.

Para la celebración del 15 de agosto, dia de las religiosas. siempre celebramos la Eucaristia en la Catedral, después ibamos a la Casa de Ejercicios; è nos ofrecia un almuerzo a todas. Nosotros preparábamos números artísticos y don Sergio, que es un actor de teatro muy, muy bueno, hacia teatro con nosotras, cantaba, participaba en los juegos: "ya, quien se canta una canción del año tanto", allà salia don Sergio cantando la canción con su grupo. Es bueno ver al Pastor desde otra perspectiva porque a veces la cara pública es con la que uno se queda ¿no?, pero al ver la cara más de la persona humana, haciendo fiesta, sobremesas simpáticas después del almuerzo, etc. nos abren a otras facetas de la persona. $Y$ eso para mi ha sido muy enriquecedor.

Don Sergio es distinto cuando está en ambiente humano. familiar que cuando está en una asamblea. La mayoria sólo tuvo acceso a esta segunda dimensión. Me recordaba a mi la frase de San Agustin: "con ustedes soy hermano y para ustedes soy Pastor", esa frase siempre la he puesto para don Sergio. Es un pastor cuando tiene que hablar como Iglesia y un cristiano cuando en la intimidad abria su corazón de amigo y hermano. Cuando está liberado del cargo de pastor. es un hermano que sabe hacer reir. hacer teatro.

\section{¿Qué aportó don Sergio a la iglesia chilena y latinoamericana?}


Cuando don Sergio era Secretario de la Conferencia Episcopal yo era secretaria de la Conferencia de Religiosos y cada mes asistia a la reunión de la Comisión Pastoral. Ahi pude ver la visión que él tenia de Iglesia. Por eso me atrevi a trabajar con él, porque yo también tengo eso que donde se hace Iglesia y se vive la Iglesia ahí quiero estar muy metida. En ese tiempo pude vivenciar al hombre de Iglesia. Don Sergio es uno de esos pastores mayores que se la han jugado por la Iglesia y uno lo ve ahi en su trabajo, con los otros. Por su participación en el CELAM, se veía su responsabilidad colegial por la vida de la Iglesia no sólo chilena, sino latinoamericana y universal. En este sentido su aporte ha sido riquísimo.

\section{¿Con qué palabra definiría usted a don Sergio?}

Yo tengo una frase que tal vez si él la escucha no le va a gustar yo digo que don Sergio es como un "roble viejo" con un cascaron externo duro, pero con un corazón distinto, el corazón de don Sergio es muy sensible, especialmente al sufrimiento de los demás yo lo he visto, lo he experimentado, muy sensible al que sufre. $Y$ entonces ese corazón que hay ahi dentro es el que cuesta descubrir, esa es mi frase si me preguntan por don Sergio estos robles antiguos, con cáscaras duras, pero dentro con una riqueza y una sensibilidad extraordinaria.

Don Sergio es muy emotivo, muy sensible frente al dolor. Cuando hoy dia lo vemos emocionarse, es por que ahora está aflorando su corazón.

\section{¿Y en su vida personal, cómo era don Sergio?}

Ese testimonio si puedo darlo bien objetivamente. Don Sergio vivió con una sobriedad extraordinaria era un Pastor pobre que no se dio lujos. Uno podria pensar que con tanto trabajo se podria haber hecho un viajecito en avión, pero él siempre viajó en bus. Iba y venía a Santiago en bus, como el común de la gente. Siempre fue muy consecuente con la pobreza. Yo, alguna vez, he tenido entrada a sus habitaciones privadas. Son de una sobriedad, de una gran pobreza diria yo, en ese sentido para mi, como religiosa, don Sergio fue una lección muy, muy fuerte. $Y$ el mismo hecho que no haya tenido casa también es significativo. $Y$ lo otro que yo sé es que nunca un pobre se fue de la Casa de Ejercicios sin que él lo despidiera con algo, incluso ha llegado a dar su propio calzado. Esa sobriedad es otra cosa que a mi me emociona y cuestiona.

Otro aspecto de don Sergio que quisiera testimoniar es su autenticidad, siempre fue un hombre de la verdad, consigo mismo y con los demás, por eso siempre guardaré su recuerdo como un hombre integro. Cuando él hablaba nunca en sus palabras hubo una sombra de doblez.

\section{¿Cómo vivió don Sergio el conflicto?}

Don Sergio se la jugó por sus ideas, las llevaba adelante aunque algunos quedaran en el camino. Cuando él veia algo, cuando estaba 
convencido de ello - 10 he visto en la reuniones del clero- el defendía su pensamiento y llevaba su idea adelante.

En la época de ia Dictadura Militar lo vi como un gran, gran Pastor en la defensa de los derechos humanos en la defensa de las personas, se las jugó. Ahi tuvo més que luchar y sufrir, andaba en todo cuando pasaba algo. Recuerdo que hubo una revuelia de los universitarios, a una niña la balearon $y$ don Sergio fue la unica persona que fue y pudo hacer orden en ese caos. Los jóvenes escucharon ia voz de don Sergio, donde habia tanta revuelta y rebeldia, donde derrepente podia reventar todo el ponia la cordura y la paz.

En ese periodo tan conflictivo, todos eslabamos muy aterrorizados. Era el miedo el que reinaba en ese tiempo y todos andábamos como protegiéndonos y defendiéndonos, por eso que ałi veo tan grande la figura de don Sergio. El no tuvo miedo a cue lo persiguieran, incluso no tuvo miedo a la muerte. Donde él veia que pasaba aigo ćllá estaba. Fue fuerte. En la misma Iglesia no siempre supimos acompanarlo y comprenderlo, por eso cuando te decia lo de ias Semanas Sociales los obstaculos venian de fuera y de dentro de la iglesia ¿Como ibamos a hacer Semanas Sociales en un ambiente asi?, Sin embargo, las Semanas Sociales se hacian apoyadas por la fuerza profética de don Sergio.

\section{¿Qué le faltó a este Pastor?}

Yo dira que en lo personá le faltó el diálogo con algunas personas, el acoger el pensamierito distinto de olro. ese podria ser un limite de su personalidad.

Y en la pastoral como tal, comn muier tengo quo decir que el ámbito de la mujer no llegó a la pastoral sino hasta ahora, somos el área infantil de la diócesis, recién nacida, como que esa parte de trabajo con la mujer, de promover a la mujer en la iglesia no tuvo un gran desarrollo. Claro que don Sergio me dijo una vez que yo no tendria nunca que quejarme de eso porque yo he sido una mujer regalcneada en este sentido, de hecho, hasta he estado presente en las reunionies de los obispos

\section{¿Cuál cree que es el legado que dęa don Sergio a la diócesis de Temuco?}

Creo que su legado está en el aspecto pastoral, es un pastor sacrificado que iba a todos los lugares, por dificil que haya sido. fue un pastor que no se cuido a si mismo sino que estuvo donde tenia que estar. Como que nos quisicra decir: no se cuiden tanto, entréguense más por el Reino, eso es un poco lo que veo. 